\title{
Budidaya Jamur Tiram Tanpa Menggunakan Plastik Baglog
}

\author{
Isnayati ${ }^{1}$, Sugeng Riyadi', Muhammad lqbal Khairunnas ${ }^{3}$ \\ ${ }^{1}$ Bandar Lampung, 35144, isnayati995@gmail.com \\ 2Bandar Lampung, 35144, sugengryd@gmail.com \\ 3Bandar Lampung, 35144 miqbalkhairunas@polinela.ac.id \\ Submisi : 17 Agustus 2019; Penerimaan : 28 September
}

\begin{abstract}
ABSTRAK
Budidaya jamur tiram sejatinya adalah pemanfaatan limbah serbuk kayu sebagai bahan baku pembuatan baglog jamur. Namun dalam perkembangannya budidaya jamur tiram menghasilkan limbah baru yang jauh lebih berbahaya dari pada bahan dasar pembuatannya yaitu plastik pembungkus baglog. Penelitian ini menggunakan metode deskriptif yaitu gambaran tentang dapat berfungsinya alat pencetak log tanpa plastik dan gambaran tentang teknik budidaya jamur tiram tanpa menggunakan plastik baglog menggunakan bak kontainer sebagai tempat penumbuhan miselia jamur tiram.

Hasil dari penelitian ini budidaya jamur tiram dapat dilaksanakan tanpa menggunakan plastik baglog namun dari segi pengerjaan menjadi lebih rumit dan membutuhkan waktu yang lebih lama dalam proses pencetakan log dan penyusunan 12 buah log dalam bak kontainer ukuran 40 Liter, miselia dapat berkembang, namun pada fase penumbuhan miselia jamur dalam bak kontainer miselia jamur saling merekatkan susunan log menjadi satu dan sulit terpisahkan.
\end{abstract}

Kata kunci : limbah plastik; miselia jamur dalam bak kontainer; pencetak log; baglog tanpa plastik.

\section{PENDAHULUAN}

\section{Latar Belakang dan Masalah}

Plastik merupakan bahan anorganik buatan yang tersusun dari bahan-bahan kimia yang cukup berbahaya bagi lingkungan. Limbah dari pada plastik ini sangatlah sulit untuk diuraikan secara alami. Untuk menguraikan sampah plastik itu sendiri membutuhkan kurang lebih 80 tahun agar dapat terdegradasi secara sempurna. Oleh karena itu penggunaan bahan plastik dapat dikatakan tidak bersahabat ataupun konservatif bagi lingkungan apabila digunakan tanpa menggunakan batasan tertentu. Selain itu jika limbah plastik termakan oleh hewan dan tanaman maka hewan dan tanaman tersebut beracun sehingga berbahaya bagi keberlangsungan rantai makanan. Limbah plastik yang terurai di dalam tanah akan menghasilkan partikelpartikel yang bisa mencemari air dan tanah. Tanah menjadi tidak subur karena banyak hewan pengurai, misal cacing tanah yang terbunuh akibat partikelpartikel tersebut, air di dalam tanah tidak bisa mengalir lancar, dan menghalangi sirkulasi udara di dalam tanah. Limbah plastik juga berperan dalam pemanasan global sehingga terjadi perubahan iklim yang ekstrem. Sejak dari proses produksi plastik sampai dengan pembuangan, plastik telah menghabiskan banyak energi dan mengemisi gas rumah kaca ke astmosfer dan penipisan lapisan ozon. Limbah plastik yang dibuang sembarangan, misalnya di sungai akan membuat banjir karena sungai dangkal akibat tumpukan limbah plastik. Jika limbah plastik dibakar juga akan menghasilkan gas karbondioksida 
sehingga mengakibatkan polusi pada udara dan pemanasan global.

Menurut Kepala Pusat Penelitian

Kimia LIPI, Agus Haryono,2017, Indonesia menjadi negara terbesar ke-2 di dunia yang membuang sampah plastik ke lautan. Konsumsi plastik di Indonesia per kapita sudah mencapai 17 kilogram per tahun dengan pertumbuhan konsumsi mencapai 6-7 persen per tahun. Sampah plastik ini dapat berubah menjadi mikroplastik yang dapat terapung di lautan dengan ukuran lebih kecil dari 1 mikron. Bahan ini menjadi berbahaya bila masuk ke dalam rantai makanan melalui ikan, biota laut, hingga masuk ke dalam tubuh manusia. (Net)

Budidaya jamur kayu adalah salah satu cara untuk melakukan pemanfaatan limbah dari usaha panglong kayu berupa serbuk kayu hasil gergajian kayu. Jamur kayu dapat tumbuh dan berkembang dalam media yang terbuat dari serbuk kayu yang dikemas dalam kantong plastic yang diistilahkan sebagai baglog. Secara harfiah baglog mengandung arti kantung (bag) media berbentuk kayu gelondongan (log). Ketika plastik media dilubangi atau sobek, dari lubang itulah akan tumbuh jamur. Proses budidaya jamur tiram yang dilakukan selama ini dimasyarakat bukan saja menghasilkan jamur sebagai produk utama tetapi juga menghasilkan limbah plastik yang turut menyumbang pencemaran lingkungan.

$\mathrm{Di}$ Indonesia, sentra produksi jamur tiram dapat dijumpai di daerah jawa barat dari kabupaten bandung (Cisarua,Cimahi-bandung sampai ke daerah lembang), diusahakan oleh petani secara perorangan maupun kelompok dalam bentuk koperasi dengan kapasitas produksi 5-8 ton setiap hari dalam bentuk jamur segar (Maulana, 2013).

Dari tabel 1 dapat disimpulkan potensi limbah plastik yang dihasilkan dari budidaya jamur tiram setiap hari sebesar $40 \mathrm{~kg}$ jika dikalikan dengan jumlah hari dalam satu tahun maka menghasilkan \pm 14 ton/tahun limbah plastik. Potensi cemaran selama plastik belum terdegradasi adalah 1000 ton selama 80 tahun. Angka cemaran ini baru didapat dari kapasitas produksi budidaya jamur tiram daerah jawa barat. Potensi cemaran limbah plastik akan lebih banyak lagi jika dipandang secara umum terhadap Budidaya jamur kayu di Indonesia.

Tabel 1. potensi limbah plastik minimum dari limbah jamur Tiram jawa barat

\begin{tabular}{|l|c|c|}
\hline Kapasitas produksi/hari & $5000-8000$ & $\mathrm{Kg}$ \\
\hline Potensi produksi/baglog & 0,5 & $\mathrm{Kg}$ \\
\hline Jumlah/Kg plastik baglog & 350 & Buah \\
\hline Menghasilkan Plastik/hari & $28,57-45,71$ & $\mathrm{Kg}$ \\
\hline
\end{tabular}

Secara tradisional, di Jepang, bibit ditanam di dalam lubang atau garisan di kayu kering. Pengeringan dilakukan dengan tenaga sinar matahari atau listrik. Dalam budidaya modern, media tumbuh yang digunakan berupa kayu tiruan (log) yang dibuat dalam bentuk silinder. Komposisi media ini berupa sumber kayu (gergaji kayu, ampas tebu), sumber gula (tepung-tepungan), kapur, pupuk $\mathrm{P}$, dan air.Media tanam jamur yang digunakan sebagai bahan produksi jamur. Pada media ini nantinya akan dikondisikan agar tumbuh jamur. Istilah baglog mengandung arti kantung (bag) media berbentuk kayu gelondongan (log). Ketika plastik media dilubangi atau sobek, dari lubang itulah akan tumbuh jamur.

Plastik didalam budidaya jamur tiram mempunyai peranan yang penting mengingat penanaman jamur tiram dilakukan secara aseptik. Komposisi media tanam jamur tiram yang 
mengandung selulosa juga sangat memungkinkan untuk mikroorganisme lain dapat tumbuh dan berkembang dalam media. Selain sebagai pembentuk media tanam, plastik baglog juga berfungsi sebagai pembatas dengan lingkungan luar media tanam untuk mencegah berkembangnya mikroorganisme lain yang tidak diharapkan dalam proses budidaya jamur tiram. Dilihat dari fungsi dan pemakaiannya dimungkinkan plastik baglog dapat digantikan dengan wadah yang dapat dipakai secara berulangulang dalam proses budidaya jamur tiram.

Selain itu media plastik juga berfungsi menciptakan faktor lingkungan yang dibutuhkan oleh pertumbuhan jamur terutama pada fase pertumbuhan miselia yang memerlukan kandungan oksigen yang relatif rendah dan karbondioksida relatif tinggi. Dengan menggunakan teknik budidaya tanpa plastik baglog demi menghindari limbah plastik jamur tiram seberapa efektifkah pengguanaan suatu wadah (wadah kontainer) beberapa log yang tersusun dalam satu wadah penanaman. Namun pada fase pembentukan tubuh buah suhu lingkungan yang diperlukan antara $16-22^{\circ} \mathrm{C}$ dengan kelembaban lingkungan cukup tinggi 95 - 98\% dengan kandungan gas oksigen relatif tinggi tetapi kebutuhan gas karbondioksida relatif rendah, yaitu dibawah 700 ppm (Maulana, 2013). Pada fase pembentukan tubuh buah jamur tiram biasanya petani jamur merusak plastik dengan cara melubangi plastik atau merobek sebagian plastik untuk memenuhi penyesuaian kondisi lingkungan. Setelah melewati fase inkubasi yang ditandai memutihnya seluruh bagian log apakah tubuh buah jamur tiram dapat terbentuk jika dikeluarkan dari wadah penanaman.
Dalam praktikum budidaya jamur konsumsi, produksi budidaya jamur kayu merupakan salah satu topik praktikum yang diselenggarakan mata kuliah tersebut. Dengan menggunakan teknik budidaya jamur tiram tanpa plastik baglog diharapkan dapat menambah wawasan baru bagi mahasiswa politeknik negeri lampung khususnya program studi hortikultura.

Berdasarkan permasalahan yang telah disebutkan, penulis selaku tenaga pendidik di lingkungan Politeknik Negeri Lampung berinisiatif untuk merancang sebuah penelitian berupa Teknik Budidaya Jamur Tiram Tanpa menggunakan plastik Baglog. Kelebihan dari teknik yang akan dilaksanakan ini diharapkan mengurangi cemaran plastik dari hasil budidaya jamur tiram, juga dapat mengurangi biaya produksi dari budidaya jamur.

Dilihat dari fungsinya plastik sebagai wadah media jamur tiram berfungsi sebagai pembentuk log dalam bentuk silinder. Diperkirakan media jamur tiram dapat dicetak seperti log tanpa menggunakan plastik dengan tingkat presan tertentu sehingga diperoleh tingkat kepadatan yang tepat.

\section{Tujuan Penelitian}

1. Memperoleh teknik baru dalam hal budidaya jamur kayu yang dapat mengurangi penggunaan modal tidak tetap (biaya oprasional) melalui pengurangan pembelian bahan plastik pembungkus baglog.

2. Memperoleh teknik baru dalam hal budidaya jamur kayu yang lebih ramah lingkungan melalui pengurangan penggunaan bahan plastik.

3. Menambah peralatan laboratorium yang tepat guna. 


\section{METODE PENELITIAN}

\section{Waktu dan Tempat Penelitian}

Penelitian akan dilakukan di Kubung Jamur Laboratorium Tanaman III, Penelitian dilakukan mulai bulan Agustus sampai dengan bulan Desember 2017.

\section{Bahan dan Alat}

Serbuk kayu, Dedak, Tepung Tapioka, Kapur Dolomit, Gibsum, Kertas Koran, Alkohol 90\%, Spritus, Clorok 5\%, Lakban,,Plastik sealer, Alat Pres baglog, Ember, Timbangan, Bak Kontainer inkubasi, Selang Air, Alat Tulis, Bak Penampung Air, Pompa Air, Alat sterilisasi, Pinset, Lampu Bunsen,Spatula, Mistar besi

\section{Rancangan Penelitian}

Penelitian ini merupakan penelitian rancang bangun proses budidaya jamur tiram tanpa plastik baglog. dilakukan dengan beberapa tahap, yakni sebagai berikut :

1. Tahap Persiapan Alat dan Bahan

2. Tahap Budidaya

\section{Pelaksanaan Penelitian}

1. Tahap Persiapan Alat dan Bahan

Alat dan bahan dikumpulkan pada satu lokasi budidaya jamur tiram agar lebih mempermudah dalam pelaksanaan budidaya jamur tiram yang akan dilaksankan. Masing-masing alat di klasifikasikan berdasarkan fungsi dan kegunaannya.

Persiapan alat pengepres adalah dengan cara memodifikasi alat pres log jamur yang umum telah banyak digunakan para petani jamur kayu. Modifikasi dilakukan dengan mengganti cetakan dengan pipa besi diameter sama dan menambah pengunci kepadatan. Prinsip kerja alat yang akan dibuat adalah untuk menyatukan media tanam menjadi log dengan cara dipadatkan, kemudian menahan tuas pengepres dengan pengunci kemudian menggoyangkan secara perlahan cetakan besi kearah atas sehingga media yang telah dipadatkan tertinggal dibagian bawah alat pres.

Persiapan alat berupa bak kontainer plastik adalah dengan cara melubangi bagian tutup bak kontainer berbentuk lingkaran diameter $7 \mathrm{~cm}$. Prinsip kerjanya lubang berfungsi untuk tempat memasukan bibit jamur pada proses penanaman dan ditutup dengan kertas koran yang dilekatkan dengan lakban. Kertas koran diperlukan untuk pertukaran oksigen dalam jumlah sedikit namun dapat mempersempit perpindahan mikroorganisme dari lingkungan sekitar.

Mesin pompa air dipersiapkan untuk mengaliri air dari drum penampungan air ke dalam ruang growing jamur tiram melalui selang dan drip pengkabut. Penggunaan Drip pengkabut air diperlukan untuk menciptakan lingkungan mikro yang baik bagi pertumbuhan jamur tiram.

2. Tahap Budidaya
a. Pembuatan Baglog
Pembuatan Baglog dimulai dengan cara mencampurkan media tanam jamur tiram secara merata berupa serbuk kayu yang telah diayak, kapur dolomit, dedak, tepung tapioka dan gibsum serta menambahkan air sebanyak $\pm 60 \%$. Setelah media merata kemudian dicetak menggunakan alat pengepres log. Satu persatu cetakan log disusun rapih dalam bak kontainer plastik lalu ditutup rapat menggunakan sealer, diperkirakan dalam satu bak kontainer memuat 20-30 log media tanam jamur tiram. Lubang diameter $7 \mathrm{~cm}$ pada tutup kontainer dilapisi plastik yang dilakban rapat.

b. Sterilisasi media.

Sterilisasi dilakukan dengan cara memasukan bak kontainer plastik yang 
telah diisi log media jamur tiram ke dalam banker sterilisas, diperkirakan memuat 20 container. Sterilisasi menggunakan bahan bakar kayu dengan cara mengalirkan uap air yang didihkan di dalam boiler pemanas air. Sterilisasi memakan waktu 8 jam pemanasan air tanpa terhenti pembakaran.

\section{c. Penanaman Jamur Tiram}

Tahap penanaman dilakukan di dalam ruang tanam secara aseptik setelah ruangan disterilisasi dengan menggunakan clorok $5 \%$ dan alkohol $90 \%$. Penanaman dilakukan setelah media didiamkan sampai mengalami penurunan suhu di bawah $40{ }^{\circ} \mathrm{C}$. Menggunakan peralatan lampu bunsen yang diisi spritus, spatula dan pinset bibit jamur tiram dimasukan ke dalam lubang berdiameter $7 \mathrm{~cm}$ setelah dibuka plastikyang menepel pada saat proses sterilisasi. Kemudian ditutup menggunakan kertas koran yang telah di panaskan diatas api bunsen (sterilisasi menggunakan panas) direkatkan menggunakan lakban. Bibit yang dimasukan ke dalam media tanam $\pm 1 / 4$ boto bibit.

\section{d. Fase inkubasi}

Pada masa inkubasi diharapkan miselia jamur tiram dapat berkembang dalam log jamur di bak kontainer plastik, diperkirakan perkembangan miselia memakan waktu 2 bulan. Selesainya fase inkubasi ditandai dengan miselia telah menutupi permukaan media tanam yaitu memutihnya seluruh permukaan media oleh jaring-jaring miselia jamur tiram.

\section{e. Fase Growing}

Fase growing jamur tiram berlangsung setelah mengalami fase inkubasi. Bak kontainer plastik di buka kemudian log dipisahkan menggunakan mistar besi untuk memutus miselia yang menempel antar log media jamur tiram. Kemudian log jamur tiram disusun dalam rak growing yang ruangannya telah dilengkapi dengan pengkabut dari instalasi pengkabut berdaya pompa air. Pada fase ini pengkabutan air dilakukan untuk memodifikasi iklim mikro dalam ruang growing. Diperkirakan dalam waktu kurang dari 14 hari dapat dilakukan proses pemanenan.

\section{HASIL DAN PEMBAHASAN}

\section{Hasil}

1. Pembuatan Alat Pengepres Baglog Tanpa Plastik.

Di dalam Pelaksanaan Pembuatan alat pengepres baglog tanpa plastik tim peneliti menghasilkan sebanyak 1 unit. Alat ini memiliki dimensi panjang $28 \mathrm{~cm}$ lebar $15 \mathrm{~cm}$ dan ketinggian $95 \mathrm{~cm}$ yang telah melalui serangkaian modifikasi. Pencetakan dilakukan jika dengan spesifikasi awal penelitian akan menghasilkan dua kali tinggi dimensi cetakan, oleh sebab itu tim peneliti mendisain ulang cetakan.

Spesifikasi alat modifikasi terakhir yang dimiliki dari alat pengepres baglog ini adalah pada bagian cetakan memiliki empat sisi engsel yang dapat dibuka untuk menghasilkan log tanpa plastik.

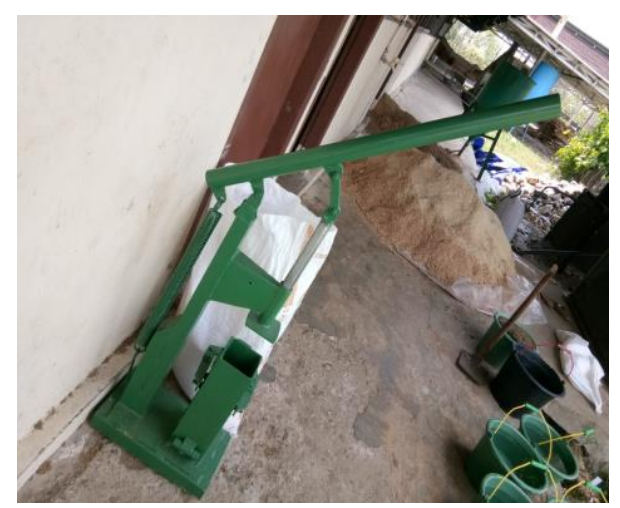

Gambar 1. Hasil akhir alat pengepres Log tanpa plastik baglog

\section{Tahapan Budidaya.}

Tahapan pelaksanaan budidaya jamur tiram tanpa plastik baglog yang didapat dari hasil penelitian ini adalah sebagai berikut : 
Tabel 2. Persentase pencampuran media tanam yang dilakukan pada budidaya jamur tiram tanpa baglog

\begin{tabular}{|l|l|l|}
\hline No & Jenis Media & Persentase \\
\hline 1 & Serbuk Gergaji & $81 \%$ \\
2 & Dedak & $10 \%$ \\
3 & Tapioka & $5 \%$ \\
4 & Kapur Dolomit & $2 \%$ \\
5 & Gibs & $2 \%$ \\
\hline
\end{tabular}

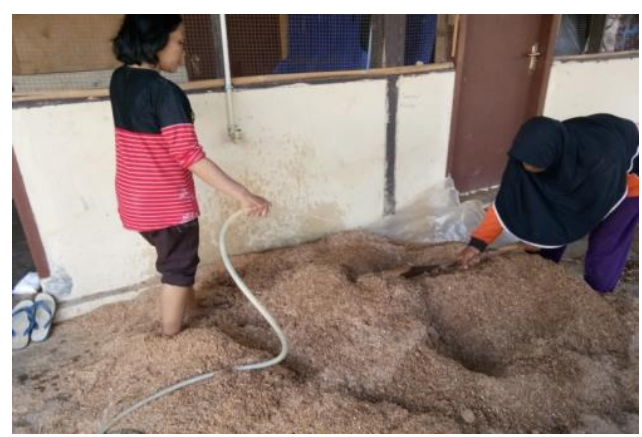

Gambar 2. Pengerjaan tahap pencampuran media tanam jamur tiram.

3. Pencetakan log jamur

Karena terdapat permasalahan teknis pada tahap pembuatan alat pengepres log tahap pencetakan pertama tim peneliti tidak menggunakan alat pengepress log, melainkan langsung memasukan campuran media ke dalam bak kontainer. Campuran media diisi padat kedalam bak kontainer yang langsung melalui tahapan sterilisasi.

Tabel 3. Berat Media Pada bak kontainer volume 40 Liter berat media

\begin{tabular}{|c|c|}
\hline No Kontainer & Berat media $(\mathrm{Kg})$ \\
\hline 1 & 24,0 \\
\hline 2 & 23,5 \\
\hline 3 & 32,0 \\
\hline 4 & 28,7 \\
\hline 5 & 26,1 \\
\hline 6 & 28,0 \\
\hline 7 & 27,0 \\
\hline 8 & 27,7 \\
\hline 9 & 28,0 \\
\hline 10 & 25,0 \\
\hline
\end{tabular}

Tahap kedua budidaya pencetakan media menghasilkan log jamur dengan ukuran $\mathrm{p} \times \mathrm{I} \times \mathrm{t}=10 \mathrm{~cm} \times$ $10 \mathrm{~cm} \times 18 \mathrm{~cm}$. Tahapan pencetakan log menggunakan alat pengepress baglog tanpa plastik adalah memasukan media ke dalam pencetak log pada posisi pencetak terpasang, lalu dipres dengan cara mendorong tuas ke arah bawah sampai media dirasa padat kemudian tuas diangkat ke atas. Selanjutnya melepas pengait cetakan untuk membuka secara perlahan keempat sisi cetakan. Media yang telah tercetak kemudian diangkat secara perlahan untuk dipindahkan dan disusun ke dalam bak kontainer.

Penyusunan media tanam yang telah dicetak menghasilkan 12 log yang tersusun dengan 2 tingkatan 3 bersap dan 2 baris.

\section{Pembahasan}

Komposisi media yang terbuat dari campuran bahan serbuk gergaji sulit untuk dibentuk tanpa ada media pembungkus. Media pembungkus yang lazim digunakan terbuat dari bahan plastik yang dapat menimbulkan limbah baru bagi lingkungan. Plastik sebagai bahan pembungkus log jamur akan membentuk log menjadi tidak hancur ketika telah melalui proses pencetakan. Pada kegiatan penelitian pencetakan media tanam harus dilakukan dengan sangat hati agar tidak menghasilkan getaran yang dapat merusak media serbuk yang telah dicetak. Kegiatan pencetakan tanpa plastik yang telah dilakukan dalam penelitian memakan waktu yang lama, jika dibandingkan dengan pengalaman peneliti praktik menggunakan plastik baglog. Jika dilakukan pencatatan waktu pencetakan kemungkinan dalam pengerjaan waktu akan didapatkan selisih waktu 5 x lebih lama jika dibandingkan dengan budidaya jamur tiram menggunakan baglog plastik. 
Tabel 4. Rangkaian kegiatan modifikasi pembuatan alat pengepres baglog tanpa plastik

\begin{tabular}{|l|l|l|l|}
\hline No & $\begin{array}{c}\text { Bentuk alat } \\
\text { Pencetak }\end{array}$ & \multicolumn{1}{|c|}{ Spesifikasi } & \multicolumn{1}{c|}{ Keterangan } \\
\hline 1. & Bentuk Tabung & $\begin{array}{l}\text { Tabung dipotang 2 bagian } \\
\text { Penempatan Engsel disamping } \\
\text { cetakan }\end{array}$ & $\begin{array}{l}\text { Hasil cetakan terbentuk namun } \\
\text { pada saat pengambilan hasil } \\
\text { cetakan terdapat kesulitan karena } \\
\text { bentuknya yang bulat. Ketika ingin } \\
\text { dikeluarkan dari alat cetakan } \\
\text { hancur. }\end{array}$ \\
\hline 2. & Bentuk balok & $\begin{array}{l}\text { Balok besi dibagi 2 dengan posisi } \\
\text { engsel dua sisi bagian bawah. }\end{array}$ & $\begin{array}{l}\text { Ketika dilakukan pengepresan tuas } \\
\text { dapat difungsikan, namun pada } \\
\text { saat tuas pengepres terangkat dan } \\
\text { pencetak dibuka hasil cetakan ikut } \\
\text { terbelah menjadi dua. Menempel } \\
\text { pada cetakan. }\end{array}$ \\
\hline 3 & Bentuk balok & $\begin{array}{l}\text { Dengan empat sisi dapat dibuka. } \\
\text { Engsel empat buah terdapat } \\
\text { dibagian bawah. }\end{array}$ & \begin{tabular}{l} 
Hasil cetakan dapat terbentuk. \\
\hline
\end{tabular} \\
\hline
\end{tabular}

Penanaman pada budidaya jamur tiram tanpa plastik baglog dilakukan dapat lebih cepat jika dibandingkan dengan penanaman menggunakan plastik baglog. Pada tahap penanaman jamur tiram tanpa plastik, log jamur disusun menjadi satu kesatuan dalam bak kontainer praktis dalam sekali menyebarkan bibit didapat 12 log sekaligus.

Miselia jamur tiram dapat merekatkan cetakan menjadi satu jika log yang semula telah dicetak disusun kembali dalam satu susunan dalam bak kontainer. Fase inkubasi dalam tahap penelitian ini dapat mematahkan hipotesis peneliti yang menyebutkan jamur tiram pada fase growing dapat tumbuh pada media log tanpa plastik baglog melalui pemisahan baglog setelah melewati fase inkubasi. Miselia jamur dapat merekatkan antara log yang disusun menjadi satu susunan dalam bak kontainer sehingga sulit dipisahkan.

Pengurangan plastik memang dapat menekan biaya bahan namun akan menimbulkan penambahan biaya tenaga kerja jika ingin melakukan proses budidaya jamur tiram tanpa plastik pembungkus log.

\section{PENUTUP}

\section{Kesimpulan}

Dari hasil dan pembahasan penelitian dapat disimpulkan bahwa budidaya jamur tiram tanpa plastik baglog dapat dilakukan pencetakan log dengan waktu pengerjaan yang lebih lama jika dibandingkan melakukan budidaya jamur tiram menggunakan plastik baglog. Miselia dapat berkembang pada fase inkubasi namun dapat merkatkan media yang telah dicetak yang disusun dalam satu susunan di bak kontainer. Pengurangan plastik memang dapat menekan biaya bahan namun akan menimbulkan penambahan biaya tenaga kerja pada proses pencetakan log dalam produksi jamur tiram tanpa plastik pembungkus $\log$.

\section{Saran}

Produksi Jamur tiram adalah pemanfaatan limbah serbuk gergaji namun menghasilkan limbah baru yang lebih berbahaya bagi lingkungan oleh sebab itu riset untuk mengurangi limbah dari proses budidaya jamur tiram sangat penting dilakukan proses penyadaran kepedulian terhadap lingkungan. 
Bagi peneliti serupa proses pencetakan menjadi hal yang sangat perlu dikonsentrasikan dalam hal budidaya jamur tiram tanpa plastik, dapat juga mencari bahan pengganti yang lebih ramah terhadap lingkungan sebagai pembungkus mengingat sifat bahan utama berupa serbuk gergaji dan kondisi mikro yang cocok untuk perkembangan jamur tiram.

\section{UCAPAN TERIMA KASIH}

Sepenuhnya penulis menyadari penelitian ini masih jauh dari sempurna, Meskipun hasil penelitian menunjukan beberapa titik kelemahan dalam budidaya jamur tiram tanpa plastik baglog, namun upaya untuk mengurangi limbah ataupun produksi bidang pertanian yang lebih ramah lingkungan harus terus dimulai agar tercapai kelestarian dan keberlanjutan. Ucapan terimakasih kepada semua pihak yang telah memberi masukan dan saran sehingga penelitian ini dapat terlaksana, kami berharap hasil penelitian ini bermanfaat bagi lembaga, PLP, mahasiswa dan juga masyarakat luas.

\section{DAFTAR PUSTAKA}

Cahyana YA, Muchrodji, Bakrun, M. 2001. Jamur Tiram Pembibitan Pembudidayaan dan Analisis Usaha. Penebar Swadaya. Jakarta

Djarijah NM \& Djarijah AS. 2001. Jamur Tiram Pembibitan Pemeliharaan dan Pengendalian HamaPenyakit. Yogyakarta: Penerbit Kanisius

Gunawan, AW. 2004. Budidaya Jamur Tiram. PT Agro Media Pustaka. Depok.
Hadrawi, J. 2014. Skripsi Kandungan Lignin Selulosa dan Hemiselulosa Limbah Baglog Jamur Tiram Putih (Pleurotus ostreatus) Dengan Masa Inkubasi yang Berbeda Sebagai Bahan Pakan Ternak.

http://ejurnal.its.ac.id/index.php/sains_se ni/article/download/16175/2899 diakses tanggal 2 maret 2017

http://elib.unikom.ac.id/download.php?id $=140377$ diakses tanggal 3 maret 2017

http://jamurkarmanwae.blogspot.co.id/ diakses tanggal 3 maret 2017

http://lipi.go.id/lipimedia/single/konsumsi -plastik-indonesia-tertinggi-keduadi-dunia/15173 diakses tanggal 2 juli 2017

http://repository.unhas.ac.id/bitstream/ha ndle/123456789/12063/skripsi.pdf ?sequence $=2$ diakses tanggal 2 maret 2017

http://www.forclime.org/merang/50-STEFINAL.pdf diakses tanggal 4 maret 2017.

http://www.unri.ac,id/jurnal/jurnalnature/v ol5(2)Abdul.pdf. diakses tanggal1 Juni 2014.

Maulana Erie Sy. 2012. Panen Jamur Tiap Musim : Panduan Lengkap Bisnis dan Budi Daya Jamur Tiram. Lily Publisher. Yogyakarta.

Parlindungan, A. K. 2000. Pengaruh konsentrasi urea dan TSP di dalam air rendaman baglog alangalang terhadap pertumbuhan dan produksi jamur Tiram Putih (Pleurotus ostreatus). Prosiding Seminar Hasil Penelitian Dosen UNRI, Pekanbaru

Susilawati dan Raharjo B. 2010. Budidaya Jamur Tiram (Pleourotus ostreatus var florida) yang ramah lingkungan (Materi Pelatihan Agribisnis bagi KMPH). BPTP Sumatera Selatan 